\title{
Desenvolvimento de um Inventário de Levantamento das Dificuldades da Decisão Profissional
}

\author{
Ricardo Primi ${ }^{12}$ \\ Alícia Maria Hernandez. Munboz \\ Cássia Aparecida Bighetti \\ Eliane Porto Di Nucci \\ Maria Carolina K. Pellegrini \\ Melissa Aparecida Moggi \\ Universidade São Francisco
}

\begin{abstract}
Resumo
Apresenta-se o desenvolvimento de um inventário baseado em um modelo da indecisão profissional que se apoia nas teorias da tomada de decisão. Aplicou-se o inventário em 227 alunos, 52,8\% de uma escola estadual e 47,2\% de uma escola particular, a maioria de 14 a 17 anos, freqüentando a oitava serie do Ensino Fundamental e segunda e terceira série do Ensino Médio. A análise fatorial indicou a presença de 17 fatores primários hierarquicamente agrupados em quatro fatores mais amplos: a) insegurança e falta de informação (Alfa 0,89); b) ênfase no busca de prestígio e retorno financeiro (Alfa 0,79); c) imaturidade para a escolha (Alfa 0,70); e, d) conflitos com pessoas significativas (Alfa 0,71). Uma ANOVA indicou que os alunos de escolas estaduais tendem a privilegiar o aspecto econômico e os alunos mais jovens apresentam um maior grau de imaturidade, atestando a validade do instrumento.

Palavras-chave: Indecisão profissional; aspiração profissional; orientação profissional; avaliação psicológica.
\end{abstract}

Development of a Questionnaire of Career Decision-Making Difficulties

Abstract

The development of a questionnaire of career decision-making difficulties based on a model of decision making process is presented. A sample of 227 Brazilian students, $52.8 \%$ from public and $47.2 \%$ from private schools, $69 \%$ with age ranging from 14 to 17 years old, attending the eighth to eleventh grades, answered the questionnaire. Factor analysis indicated 17 factors hierarchically organized in four broader secondary factors: a) indecisiveness and lack of information (Alpha .89); b) search for prestige and financial support (Alpha .79); c) immaturity (Alpha .70); and d) external conflicts with significant persons (Alpha .71). An ANOVA showed that the public school students tend to give higher importance to economical aspects and the eighth graders tend to be more immature than tenth and eleventh graders.

Keywords: Career indecision; occupational-choice; occupational-aspirations; psychological assessment.

A ocupação profissional tem sido considerada um dos grandes pólos da vida do indivíduo. Uma escolha adequada é almejada por todos e acarreta benefícios para as pessoas e para a sociedade. Assim, a escolha profissional assume grande importância no plano individual, já que envolve a definição das futuras experiências profissionais, significando principalmente a definição de quem ser, muito mais do que a escolha do que fazer (Bohoslavsky, 1987; Gati, Krausz \& Osipow, 1996).

${ }^{1}$ Endereço para correspondência: Universidade São Francisco/Centro de Ciências Humanas e Sociais, Rua Alexandre Rodrigues Barbosa, 45, 13251-900, Itatiba, SP. E-mail: rprimi@mpc.com.br

2 Este estudo é parte de uma pesquisa em andamento investigando as relações entre características de personalidade e escolha profissional financiada pelo Programa de Estímulo à Pesquisa Científica (PEPCI, USF, №. 98329). Os autores gostariam de agradecer um dos revisores anônimos, cujos comentários foram muito importantes para a melhoria deste artigo.
O processo de escolha profissional é um momento de importância significativa para o adolescente e, como não poderia deixar de ser, freqüentemente é repleto de dificuldades e conflitos. A orientação profissional oferece ajuda nesse momento propiciando ao adolescente condições para uma experiência de auto-reflexão e aprendizado, visando uma escolha ajustada e madura (Müller, 1988). Para isso, os profissionais que trabalham nessa área podem fazer uso de instrumentos diagnósticos específicos que os ajudem a compreender as dificuldades enfrentadas pelos adolescentes. Entretanto, observa-se uma deficiência nos instrumentais disponíveis para esse fim. Por esta razão, esse trabalho objetivou desenvolver um instrumento de levantamento das principais dificuldades da escolha profissional.

A escolha profissional é um processo complexo de decisão. Nesta situação uma pessoa precisa tomar uma 
decisão a partir de um conjunto de opções disponíveis. É fundamental que ela considere suas características pessoais simultaneamente com as características das opções. A escolha deve buscar contemplar seus anseios pessoais sem, contudo, desconsiderar a realidade do mercado de trabalho (Gati e cols., 1996).

Fazem parte dessa situação complexa vários fatores que dificultam e levam ao impasse da indecisão profissional. Observou-se na literatura a existência de vários enfoques teóricos privilegiando diferentes aspectos da indecisão profissional (Chartrand \& Camp, 1991; Santos, 1997; Santos \& Coimbra, 1995). A seguir, exemplificaremos alguns desses enfoques e, ao final, o modelo adotado na construção do inventário que foi objeto deste estudo.

O trabalho de Bordin e Kopplin (1973) exemplifica as teorias que enfatizam os conflitos psicodinâmicos vividos no momento da escolha profissional. Os autores conceberam a escolha profissional como um dos períodos de transição integrante do desenvolvimento da identidade adulta. Argumentaram que "a escolha profissional envolve uma negociação visando a integração de nosso autoconceito - incluindo as necessidades individuais, identificações, aptidões, estilos de defesa e valores - com o papel profissional" (p. 154). Enfatizaram o conflito vivido pelo sujeito quando este percebe motivações que não são facilmente integradas aos papéis profissionais. Propuseram que, em um extremo, o auto-conceito poderia ser caracterizado como uma identidade operacional claramente diferenciada, facilitando a integração aos papéis profissionais. Em outro extremo, ele poderia ser caracterizado como identidade difusa conflituosa, dificultando essa integração.

A partir da experiência clínica com os casos atendidos no Centro de Aconselhamento da Universidade de Michigan, Bordin e Kopplin (1973) desenvolveram um sistema de classificação para qualificar os diferentes conflitos que observavam nos alunos que os procuravam. Além disso, esse sistema ordenava os tipos de conflito em função do grau de severidade. Apontava desde níveis mais propícios à integração, ou mais próximos da dissolução da indecisão, até níveis mais severos nos quais a indecisão profissiona era a expressão de uma patologia preexistente. Propuseram cinco categorias: a) dificuldade de síntese (ex.: experiência restrita, obstáculos financeiros), b) problemas de identidade (inexistência de traços claros de identidade, auto-conceito distorcido), c) conflitos de gratificação (profissões ao mesmo tempo gratificantes e frustrantes), d) orientação à mudança (o uso da escolha profissional como um meio de mudança de identidade), e) patologia evidente (questão da escolha profissional vista como um sintoma de aspectos patológicos preexistentes). A identificação dos conflitos vividos pelas pessoas é importante pois, segundo os autores, para cada tipo de conflito, a orientação profissional deverá focalizar questões distintas.

Um outro importante enfoque teórico encontrado procura entender o processo de desenvolvimento associado à escolha profissional (Crites, 1969; Super, 1953). As teorias com este enfoque são denominadas abordagens desenvolvimentais. Determinados percursos desenvolvimentais conduzem a uma maior ou menor maturidade vocacional, entendida como a capacidade que o sujeito desenvolve para resolver tarefas relacionadas à sua carreira profissional, inclusive a escolha de uma profissão. A abordagem desenvolvimental procura definir os estágios que precedem a maturidade vocacional e consequentemente contribuem para a compreensão dos fatores dificultadores da escolha profissional (Santos \& Coimbra, 1995).

Neste estudo, entendemos a maturidade vocacional como o produto de um processo que se dá ao longo do desenvolvimento e por meio do qual a pessoa vai construindo uma definição do que quer e o que pode fazer na vida em termos profissionais. Sendo parte do desenvolvimento geral, essa maturidade depende da integração de várias experiências de vida que precedem o momento da escolha profissional. Diversos fatores associados a essas experiências podem prejudicar seu desenvolvimento, sendo possível dividi-los em duas categorias: os que se referem ao ambiente e os que se referem ao sujeito (Duarte, 1997; Mangas, 1997; Santos, Ribeiro \& Campos, 1997).

O primeiro grupo aborda dois microssistemas desenvolvimentais importantes na vida do indivíduo, o contexto educacional e o familiar. A qualidade das relações estabelecidas nesses contextos influencia diretamente o desenvolvimento da maturidade vocacional, podendo prejudicá-la quando são pouco estimuladores à curiosidade e à autonomia, por exemplo.

O segundo grupo aborda os aspectos afetivos, intelectuais e sociais do indivíduo. Como exemplo desses aspectos pode-se citar: a) dependência emocional, b) falta de motivação, c) problemas relacionados ao autoconceito, d) rigidez de pensamento e raciocínio infantil, e) pouca informação prática a respeito da profissão, com percepções mais subjetivas de carreira, e f) dificuldades de adaptação a diferentes situações, adotando atitudes rígidas.

Esses fatores interferem negativamente na formação de uma identidade profissional bem definida. Por outro lado, pode-se indagar: que características de personalidade 
apresentam as pessoas com uma identidade profissional melhor delineada e mais decididas ? Em nossa opinião, a resposta para essa questão vem dos estudos sobre os interesses profissionais, remetendo a um outro enfoque teórico presente na literatura, chamado de abordagem diferencial. Esse enfoque procura descrever as diferenças individuais, principalmente de personalidade, entre pessoas indecisas e decididas, ou ainda, quais são as características mais salientes de pessoas de diferentes áreas profissionais (Santos \& Coimbra, 1995). Referindo-se a esse enfoque, utilizaremos a idéia de tipo profissional bem definido significando um conjunto de características de personalidade (traços característicos, interesses e aptidões) prototípicos das pessoas que ocupam áreas profissionais específicas. A nosso ver, as teorias diferenciais têm contribuído para a definição descritiva desses tipos profissionais.

À medida que as pessoas vão crescendo, experimentando a realidade e adquirindo mais conhecimentos sobre as atividades profissionais, vão cristalizando um conjunto de interesses em temas cada vez mais específicos. O modelo hexagonal de John L. Holland (Holland, 1963), um dos trabalhos mais conhecidos e respeitados na literatura atual (Gati, 1991), sistematiza uma tipologia caracterizando os protótipos ou casos mais extremos de tipos profissionais. Ele propõe seis tipos básicos: Realista (R), Investigador (I), Artístico (A), Social (S), Empreendedor (E) e Convencional (C).

O Tipo R é voltado para realizações observáveis e concretas e prefere trabalhar mais com máquinas, eventos e coisas do que com pessoas. Tem como valores principais as recompensas financeiras por realizações observáveis. O Tipo I é voltado à exploração intelectual e prefere mais o pensar do que o agir; é mais introvertido e asocial, evitando atividades persuasivas; os valores principais são o conhecimento e a aprendizagem. O Tipo A é voltado às atividades artísticas, musicais e literárias; é a-social como o tipo I mas é mais emotivo; necessita de atividades expressivas individuais; evita rotinas e regras e tem por valores principais a criatividade, a estética e as emoções. O Tipo S gosta de atividades de ajuda, ensino e tratamento às pessoas, preferindo, portanto, lidar com as pessoas a lidar com atividades mecânicas e técnicas. Apresenta também uma maior necessidade de atenção, tende a ser oralmente dependente e tem por valor principal o bem-estar social. O Tipo E prefere atividades nas quais pode dominar, persuadir e liderar os outros; tende a ser oralmente agressivo; evita atividades intelectuais complicadas que requerem esforço prolongado; tem por valores o dinheiro e o status. O Tipo $\mathrm{C}$ prefere atividades estruturadas nas quais deve seguir ordens claras evitando, Psicologia: Reflexão e Crítica, 2000, 13(3), pp.451-463 portanto, situações confusas; tende a ser conformista; tem por valor principal o dinheiro e o poder em ocupações sociais.

Obviamente, as tendências apresentadas não são mutuamente exclusivas, isto é, as pessoas geralmente apresentam características pertencentes a mais de um tipo. Geralmente, a caracterização das tendências individuais é feita por um código de dois dígitos referindo-se às duas dimensões (tipos) mais marcantes.

Como pode ser observado, esse sistema tipológico aglomera características de personalidade e interesses profissionais. Isto é coerente com a noção de que a cristalização dos interesses seria a expressão de tipos diferenciados de personalidade. Quando o indivíduo faz a escolha profissional ele está buscando combinar o tipo dominante de personalidade com as características da profissão. Como escreve Holland (1963): "No momento da escolha profissional a pessoa, em certo sentido, 'busca' por ambientes os quais são congruentes com suas orientações pessoais" (p. 548)

Quando se estuda as relações entre personalidade e interesses, geralmente encontram-se associações significativas. Por exemplo, Vieira e Ferreira (1997) encontraram associações entre necessidade de realização, compreensão e resistência com o tipo Investigador; necessidade de afiliação, apoio, compreensão e menos autonomia com os tipos artístico e social; necessidade de dominância, exibição e prazer com o tipo empreendedor; e necessidade de ordem e menos autonomia com o tipo convencional. Para os leitores interessados nas descobertas recentes sobre as relações entre interesse e personalidade, sugere-se a leitura dos trabalhos de Ackerman (1996) e Ackerman e Heggestad (1997).

A partir deste enfoque, a indecisão profissional pode ser entendida como uma cristalização insuficiente dos interesses que impede que o indivíduo faça a seleção de um caminho profissional específico (Gati e cols., 1996). Quanto mais indiferenciado for o perfil tipológico, considerando que eles representam com razoável adequação as áreas de interesse do homem moderno, maior será a indecisão. Essa conceituação da indecisão profissional é congruente com um dos problemas mais freqüentes encontrados por Bordin e Kopplin (1973) em sua amostra: os problemas de identidade. Em síntese, os enfoques tratados anteriormente pontuam que um dos elementos mais importantes subjacentes à indecisão profissional é a existência de uma identidade difusa, não delineada, que dificulta uma escolha em direção a uma área profissional específica.

Gati e colaboradores (1996) exemplificam um outro enfoque encontrado na literatura, o qual propõe a divisão 
das dificuldades da escolha profissional tomando como base o processo geral de tomada de decisão. Como afirmam:

"De acordo com a teoria normativa da tomada de decisão, a melhor escolha é aquela que mais ajuda a pessoa a realizar suas metas. Essas metas são representadas pelas preferências individuais aos vários atributos das alternativas de escolh em consideração. Uma decisão racional deve escolher alternativa que apresente um nível máximo de utilidade, sendo que a utilidade de cada alternativa é uma função da lacuna percebida entre as preferências individuais e as características das alternativas de escolha representadas pelos seus atributos." (p. 511)

As dificuldades foram divididas em dois grupos principais: aquelas existentes antes do início da escolha e as existentes durante a escolha. Como mostra a Tabela 1 as dificuldades antes do início da escolha referem-se à imaturidade geral em relação à decisão profissional. As dificuldades vividas durante o processo referem-se basicamente à insuficiência de informações consistentes, tanto sobre si mesmo, quanto sobre as áreas profissionais, dificultando a decisão segundo o critério de utilidade.

Tabela 1. Matriz de Conteúdo do Construto da Indecisão Profissional

Dificuldades antes do início do processo de escolha: Falta de preparo

Falta de Motivação

Indecisão

Mitos (expectativas irracionais)

Dificuldades durante o processo de escolha:

Falta de informação

Sobre o processo de decisão profissional

Sobre si próprio

Sobre as profissões

Sobre maneiras de obter informação

Informações inconsistentes

Conflitos internos

Conflitos externos

(Adaptada da taxonomia de Gati, Krausz \& Osipow, 1996)

Algumas relações podem ser estabelecidas entre este sistema e as dificuldades propostas pelos estudos anteriormente mencionados. Como foi apontado, um dos elementos subjacentes ao impasse da indecisão é a existência de uma identidade difusa, não delineada. Do ponto de vista da pessoa que está no momento de tomada de decisão sobre a carreira profissional, essa condição é experienciada por uma percepção de falta de informação.
Portanto, pode-se dizer que o sistema taxonômico de Gati e colaboradores (1996) operacionaliza o conceito de identidade difusa em elementos da experiência interna de quem a vive e as conseqüentes manifestações observáveis no comportamento. O sistema incorpora também os conflitos inerentes ao processo de escolha, embora não apresentem a mesma quantidade de detalhes como o sistema de Bordin e Kopplin (1973). O sistema acrescenta, ainda, um subgrupo de fatores relacionados à falta de preparo e que estão, portanto, associados ao elemento maturacional da escolha.

O propósito do presente estudo foi desenvolver um inventário de levantamento das dificuldades da escolha profissional aplicando o sistema taxonômico de Gati e colaboradores (1996) apresentado na Tabela 1. A escolha deste sistema pautou-se nas considerações apresentadas acima, isto é, na vantagem que ele apresenta na operacionalização do elemento principal da indecisão profissional - a identidade difusa - em uma definição propícia à criação de itens de auto-relato, isto é, à percepção de falta de informação. Esse artigo apresenta a criação do instrumento e o estudo de suas características psicométricas.

\section{Método}

\section{Participantes}

Participaram deste estudo 227 alunos de duas escolas da região de Campinas, uma da rede particular e a outra da rede pública de ensino, pertencentes à oitava série do Ensino Fundamental e às segunda e terceira séries do Ensino Médio. Na Tabela 2 pode-se observar o número de alunos em função do tipo de escola, sexo e série. O nível de escolaridade dos pais e a profissão que eles exerciam eram bem diferentes considerando o tipo de escola. Cerca de 53,8\% dos pais dos alunos da rede particular exerciam profissões que requeriam nível

Tabela 2. Distribuição dos Alunos por Tipo de Escola, Sexo e Série

\begin{tabular}{ccccc}
\hline & \multicolumn{4}{c}{ Tipo de Escola X Sexo } \\
\cline { 2 - 5 } Série & $\mathrm{M}$ & $\mathrm{F}$ & $\mathrm{M}$ & $\mathrm{F}$ \\
\hline $8^{\mathrm{a}}$ & 12 & 18 & 28 & 30 \\
$2^{\mathrm{a}}$ & 32 & 34 & 12 & 17 \\
$3^{\mathrm{a}}$ & 7 & 17 & 11 & 7 \\
\hline
\end{tabular}

Nota. Dentre os 227, alunos dois não apresentaram informações suficientes para essa classificação. 
superior enquanto que somente $4,4 \%$ dos pais dos alunos da rede pública exerciam profissões de nível superior. Com base nesta informação considerou-se que os dois subgrupos diferiam quanto ao nível sócio econômico.

As idades dos alunos variaram de 14 a 21 anos, com média de 16,22 e desvio-padrão 1,51. As faixas de idade com maiores concentrações foram: 14 (17,9\%), 16 $(26,4 \%)$ e $17(24,7 \%)$ anos.

\section{Materiais e Procedimentos}

$\mathrm{O}$ instrumento desenvolvido, chamado Inventário de Levantamento das Dificuldades da Decisão Profissional (IDDP), constituiu uma versão piloto dividido em três partes: uma seção de identificação, outra seção com questões gerais sobre a escolha profissional e uma terceira seção com 81 itens sobre as dificuldades da escolha profissional (vide Anexo A). A construção do IDDP seguiu os seguintes passos:

1) Revisão da literatura internacional sobre as dificuldades da escolha profissional e seleção de uma definição de conteúdo desse construto que fundamentasse a criação de itens para o inventário. Como foi apresentado na introdução, selecionou-se a definição proposta por Gati e colaboradores (1996) apresentada na Tabela 1.

2) Elaboração de itens a partir das categorias definidas pela matriz de conteúdo. Após a análise do significado das categorias, os autores elaboraram 155 itens preliminares. Esses itens foram revisados e aqueles que possuíam maior qualidade foram retidos para a versão piloto do IDDP. Os critérios de seleção foram: objetividade, clareza, redação e pertinência. Essa análise resultou em uma versão com 81 itens.

3) Organização dos itens em escala tipo Likert desde (Discordo Totalmente) até 7 (Concordo Totalmente).

A apreciação geral da versão piloto do inventário indicou que ele satisfez o propósito de inventariar de maneira abrangente as dificuldades apontadas no modelo de Gati e colaboradores (1996). Ele é de aplicação simples, podendo ser completado em 25 minutos.

Inicialmente, na fase de coleta de dados, enviou-se uma carta à direção das escolas solicitando a permissão para o desenvolvimento da pesquisa. Os diretores autorizaram a aplicação do questionário durante o período normal de aulas. $\mathrm{Na}$ aplicação os pesquisadores se apresentaram, explicaram os objetivos da pesquisa, esclareceram que não se tratava de avaliação de aptidão e informaram que, para quem desejasse, os dados estariam disponíveis na direção da escola, após a análise dos dados. Obtida a concordância dos alunos, as instruções foram lidas e os alunos foram orientados para que procurassem Psicologia: Reflexão e Crítica, 2000, 13(3), pp.451-463 responder da melhor forma possível. Não houve rejeição quanto à participação, mas três alunos responderam sem a necessária seriedade, o que foi evidenciado por respostas irônicas a algumas questões (Por ex.: "Que profissional você deseja ser: Lixeiro, Traficante, etc. ...”). Os questionários desses alunos foram eliminados da análise.

\section{Resultados e Discussão}

Um primeiro objetivo da análise foi investigar como os itens poderiam ser reorganizados em subgrupos de modo que refletissem dificuldades relativamente distintas e independentes da escolha profissional. Isso foi feito por meio de uma análise fatorial exploratória em duas etapas: análise fatorial dos itens e análise fatorial de segunda ordem dos escores fatoriais.

\section{Análise Fatorial dos Itens}

$\mathrm{Na}$ primeira etapa calculou-se a matriz de correlação entre os itens e, em seguida, efetuou-se uma análise fatorial por componentes principais dessa matriz. Optou-se por reter os fatores com autovalores maiores que um, já que nesse caso, condizente com uma atitude exploratória, buscava-se o maior número possível de subgrupos de itens e não a determinação exata do número de fatores subjacentes ao instrumento. Efetuou-se a rotação varimax para obter uma estrutura de fatores mais simples e independente possível.

Essa análise resultou em 26 fatores que, em conjunto, explicaram aproximadamente $70 \%$ da variância total. Examinou-se, então, a carga fatorial dos itens para a formação dos subgrupos. Nos casos em que o item se associasse a mais de um fator optou-se por mantê-lo somente em um deles. Os critérios pelos quais julgou-se a pertinência a um dos fatores foram dois: a magnitude da carga fatorial (igual ou maior que 0,30 ) ou a semelhança de conteúdo entre o item e o fator.

Em seguida, examinou-se o conteúdo dos itens agrupados para a definição do significado psicológico dos fatores. Essa análise descartou os fatores 18, 20 e 22 a 26 por estes serem compostos por poucos itens e terem pouca relevância quanto ao significado psicológico.

$\mathrm{Na}$ Tabela 3 apresentam-se as descrições dos fatores após essa análise. Pode-se notar que nem todos os fatores significam dificuldades relacionadas à decisão. Os fatores REAL e ECON indicam a natureza das motivações presentes no processo de consideração das opções profissionais. O Fator NARCI parece indicar uma tendência à autovalorização e a conseqüente preocupação com o prestígio que as opções profissionais podem 
456 Ricardo Primi, Alicia Hernandez, Munboz, Cássia Aparecida Bighetti, Eliane Porto Di Nucci, Maria Carolina K. Pellegrini es Melissa Aparecida Moggi

Tabela 3. Descrições dos Fatores Obtidos na Análise Fatorial Exploratória, Estatísticas Descritivas e Consistência Interna das Escalas

\begin{tabular}{|c|c|c|c|c|c|c|c|c|}
\hline Fator & Descrição & Código & Min. & Máx. & $M$ & $d p$ & Alfa & $\begin{array}{l}\mathrm{N}^{\circ} \text { de } \\
\text { itens }\end{array}$ \\
\hline 1 & $\begin{array}{l}\text { Falta de Informação sobre o self, } \\
\text { processo de escolha e profissões }\end{array}$ & INFO & 1,00 & 6,56 & 3,25 & 1,20 & 0,77 & 8 \\
\hline 2 & Indecisão & IND & 1,00 & 6,71 & 3,17 & 1,29 & 0,78 & 7 \\
\hline 3 & $\begin{array}{l}\text { Conflitos externos com a família ou } \\
\text { pessoas significativas }\end{array}$ & CONFLEX & 1,00 & 6,17 & 2,33 & 1,29 & 0,74 & 6 \\
\hline $4^{a}$ & Falta de apoio da família e colegas & APO & 1,00 & 7,00 & 3,99 & 1,66 & 0,74 & 4 \\
\hline 5 & $\begin{array}{l}\text { Falta de estratégias para obtenção de } \\
\text { informações }\end{array}$ & ESTR & 1,00 & 6,80 & 3,15 & 1,42 & 0,69 & 5 \\
\hline 6 & Preferências diversificadas & DIV & 1,00 & 7,00 & 3,92 & 1,54 & 0,72 & 5 \\
\hline 7 & Ênfase na realização & REAL & 1,00 & 7,00 & 5,29 & 1,30 & 0,50 & 4 \\
\hline 8 & Desmotivação e aversão & AVER & 1,00 & 7,00 & 2,49 & 1,49 & 0,64 & 4 \\
\hline 9 & Conflito entre interesse e habilidade & CONFLIN & 1,00 & 7,00 & 2,52 & 1,77 & 0,66 & 2 \\
\hline 10 & $\begin{array}{l}\text { Ênfase nos aspectos econômicos e de } \\
\text { prestígio }\end{array}$ & $\mathrm{ECON}$ & 1,17 & 7,00 & 4,63 & 1,28 & 0,73 & 5 \\
\hline 11 & Decisão passiva & PASS & 1,00 & 7,00 & 3,66 & 1,54 & 0,50 & 3 \\
\hline 12 & Mitos disfuncionais I: escolha salvadora & SALV & 1,00 & 7,00 & 3,76 & 1,84 & 0,51 & 2 \\
\hline 13 & Obstáculo financeiro & FINAN & 1,00 & 7,00 & 3,36 & 1,56 & 0,52 & 3 \\
\hline 14 & Insegurança quanto ao self & INSEG & 1,00 & 7,00 & 3,51 & 1,41 & 0,55 & 3 \\
\hline 15 & Imaturidade & IMAT & 1,00 & 7,00 & 2,68 & 1,60 & 0,48 & 2 \\
\hline 16 & Mitos disfuncionais II: escolha imutável & IMUT & 1,00 & 7,00 & 3,26 & 1,57 & 0,53 & 3 \\
\hline 17 & Auto admiração, narcisismo, ego inflado & NARCI & 1,00 & 7,00 & 3,64 & 1,25 & 0,53 & 4 \\
\hline
\end{tabular}

${ }^{a}$ Nesse fator todos os itens foram invertidos para que o escore significasse falta de apoio e não apoio familiar como os itens originais referem.

oferecer. Os fatores restantes indicam as várias facetas da indecisão profissional que o IDDP inventariou.

Para a segunda etapa da análise calcularam-se, para cada aluno, os escores nos 17 fatores definidos na primeira etapa. Inicialmente inverteu-se a pontuação dos itens que tiveram carga fatorial negativa para que tivessem o mesmo sentido que os outros. Em seguida, calcularamse os escores fatoriais somando-se as respostas aos itens de um determinado fator e dividindo-se a soma obtida pelo número de itens. Na Tabela 3 apresentam-se as médias desses escores, os desvios-padrão, os valores mínimos e máximos e a consistência interna pelo coeficiente alfa (Cronbach, 1996).

De modo geral, os fatores com maior média de concordância foram REAL e ECON. Os fatores com a menor média de concordância foram CONFLEX, AVER, CONFLIN, IMAT. Observa-se uma tendência à concordância nos itens que referem-se a aspectos positivos como, por exemplo, a ênfase na realização e

tendência à discordância em itens que referem aspectos intensos negativos como, por exemplo, a aversão à escolha.

Observa-se que seis fatores tiveram coeficientes de consistência interna razoáveis (acima de 0,70 ) a despeito do baixo número de itens em alguns casos. Os fatores restantes tiveram coeficientes baixos, possivelmente pelo número reduzido de itens.

\section{Análise Fatorial de Segunda Ordem dos Escores} Fatoriais

$\mathrm{Na}$ segunda etapa da análise efetuou-se a análise fatorial de segunda ordem da matriz de correlação entre os fatores. Como pode ser observado na Tabela 4, mesmo após a rotação varimax ainda existia covariância entre os fatores justificando, portanto, essa análise.

Inicialmente efetuou-se a análise fatorial pelo método dos componentes principais da matriz apresentada na Tabela 4. Solicitou-se a extração de fatores com autovalores maiores do que um. Pela análise do 
Tabela 4. Matriz de Correlação entre os Fatores

\begin{tabular}{|c|c|c|c|c|c|c|c|c|c|c|c|c|c|c|c|c|}
\hline Fatores & 1 & 2 & 3 & 4 & 5 & 6 & 7 & 8 & 9 & 10 & 11 & 12 & 13 & 14 & 15 & 16 \\
\hline 1. INFO & - & & & & & & & & & & & & & & & \\
\hline 2. IND & 51 & - & & & & & & & & & & & & & & \\
\hline 3. CONFLEX & 15 & 29 & - & & & & & & & & & & & & & \\
\hline 4. APO & -07 & -24 & -12 & - & & & & & & & & & & & & \\
\hline 5. ESTR & 50 & 37 & 24 & -09 & - & & & & & & & & & & & \\
\hline 6. DIV & 38 & 37 & 13 & -13 & 31 & - & & & & & & & & & & \\
\hline 7. REAL & -25 & -24 & -29 & -03 & -18 & -06 & - & & & & & & & & & \\
\hline 8. AVER & 27 & 35 & 22 & -01 & 20 & 34 & -32 & - & & & & & & & & \\
\hline 9. CONFLIN & 32 & 33 & 26 & -16 & 33 & 26 & -25 & 23 & - & & & & & & & \\
\hline 10. ECON & 05 & 15 & 09 & -33 & 04 & 18 & -21 & 16 & 05 & - & & & & & & \\
\hline 11. PASS & 08 & 11 & -01 & -02 & 02 & 16 & -07 & 18 & 10 & 14 & - & & & & & \\
\hline 12. SALV & 08 & 16 & 08 & -09 & 07 & 12 & -15 & 14 & 09 & 31 & 10 & - & & & & \\
\hline 13. FINAN & 35 & 34 & 16 & -22 & 33 & 27 & -02 & 07 & 20 & 07 & 07 & 15 & - & & & \\
\hline 14. INSEG & 46 & 43 & 24 & 01 & 32 & 16 & -17 & 20 & 21 & -10 & -02 & -05 & 20 & - & & \\
\hline 15. IMAT & 20 & 21 & 15 & 00 & 14 & 19 & -21 & 36 & 26 & 07 & 38 & 11 & 05 & 18 & - & \\
\hline 16. IMUT & -07 & 09 & 19 & -18 & 00 & -15 & -13 & 04 & 05 & 15 & -01 & 18 & 04 & -09 & 08 & - \\
\hline 17. NARCI & -01 & 16 & 10 & -39 & 04 & 12 & -08 & 06 & 09 & 50 & 23 & 21 & 15 & -06 & 09 & 23 \\
\hline
\end{tabular}

Nota. Os indicadores decimais (zero vírgula) foram omitidos para conservar espaço.

gráfico scree inferiu-se a existência de quatro fatores com fatores considerando, principalmente, as facetas que maior peso (Carrol, 1985). Efetuou-se novamente a análise fatorial restringindo a extração para quatro fatores. $\mathrm{Na}$ Tabela 5 são apresentados os resultados dessa análise.

A solução com quatro fatores explicou $51,47 \%$ da apresentaram carga igual ou maior do que 0,40 .

O Fator 1 contém um componente de falta de informação (INFO e ESTR), aliado ao componente de insegurança quanto ao processo de tomada de decisão variância total. A seguir são comentados cada um dos (IND, INSEG, DIV e CONFLIN). Ainda inclui aspectos

Tabela 5. Resultados da Análise Fatorial de Segunda Ordem

\begin{tabular}{|c|c|c|c|c|c|}
\hline \multirow[b]{2}{*}{ Faceta } & \multicolumn{5}{|c|}{ Fatores de Segunda Ordem } \\
\hline & Fator 1 & Fator 2 & Fator 3 & Fator 4 & ${ }^{a} \mathrm{~h}^{2}$ \\
\hline INFO & 0,77 & & & & 0,63 \\
\hline ESTR & 0,70 & & & & 0,50 \\
\hline IND & 0,69 & & & & 0,57 \\
\hline INSEG & 0,62 & & & & 0,50 \\
\hline FINAN & 0,61 & & & & 0,48 \\
\hline DIV & 0,57 & & 0,34 & & 0,52 \\
\hline CONFLIN & 0,48 & & & & 0,34 \\
\hline NARCI & & 0,77 & & & 0,61 \\
\hline $\mathrm{ECON}$ & & 0,71 & & & 0,55 \\
\hline $\mathrm{APO}$ & & $-0,67$ & & & 0,55 \\
\hline SALV & & 0,44 & & & 0,27 \\
\hline IMAT & & & 0,72 & & 0,58 \\
\hline PASS & & & 0,70 & & 0,60 \\
\hline AVER & & & 0,59 & 0,30 & 0,51 \\
\hline REAL & & & & $-0,68$ & 0,55 \\
\hline CONFLEX & 0,30 & & & 0,61 & 0,47 \\
\hline IMUT & & 0,39 & & 0,55 & 0,50 \\
\hline Soma das cargas ao quadrado & 3,14 & 2,19 & 1,79 & 1,63 & \\
\hline Proporção da variância & 18,48 & 12,89 & 10,51 & 9,58 & \\
\hline
\end{tabular}

Psicologia: Reflexão e Crítica, 2000, 13(3), pp.451-463 
de obstáculos financeiros (FINAN). As associações encontradas sugerem que este fator representou a dificuldade geral de tomada de decisão profissional Pode-se inferir que essa dificuldade esteja associada à falta de clareza sobre si mesmo (identidade difusa), o que levaria a pessoa a relatar a percepção de falta de informação, o conflito entre opções e a insegurança em decidir por um caminho específico.

O Fator 2 não corresponde à indecisão quanto à escolha, mas sim à tônica nos componentes econômico e de prestígio social oferecidos pelas profissões (ECON) Também é interessante notar a relação dessa ênfase com uma tendência à autovalorização e busca de prestígio (NARCI) e o relato de apoio familiar (APO). Aparece também uma tendência a conceber a profissão como uma forma de resolução de problemas pessoais (SALV).

O Fator 3 parece estar associado à falta de motivação geral para a tomada de decisão (IMAT, PASS, AVER) Essa indisposição não necessariamente representa dificuldade. Resultados altos nesse fator podem ser pertinentes entre alunos mais jovens e impertinentes entre alunos mais velhos prestes a concorrer a uma vaga na universidade nos processos seletivos.

O Fator 4 possivelmente associa-se aos conflitos externos, isto é, desaprovação do meio quanto à escolha (CONFLEX). É interessante notar que está associada a esse conflito a concepção da escolha profissional como algo imutável (IMUT) e uma tendência a atribuir pouca importância aos aspectos de realização (REAL). Também aparece uma pequena tendência à aversão ao tema da escolha profissional.

Os coeficientes de consistência interna dos quatro fatores de segunda ordem foram respectivamente: 0,89 0,79; 0,70; 0,71. Portanto, atingiram níveis de altos a razoáveis.

\section{As Diferenças quanto ao Tipo de Escola e Série}

Investigou-se a utilidade diagnóstica do IDDP na exploração das possíveis diferenças existentes entre os alunos de escolas estaduais e privadas e entre alunos de séries diferentes. Essa investigação foi feita por meio da análise de variância (ANOVA). Inicialmente calcularamse os escores fatoriais de segunda ordem somando-se os escores nas facetas (escores fatoriais de primeira ordem) e dividindo-se a soma obtida pelo número de facetas. $\mathrm{O}$ Fator 1 incluiu as facetas INFO, ESTR, IND, INSEG FINAN, DIV e CONFLIN. O Fator 2, as facetas NARCI, ECON, APO e SALV. O Fator 3, as facetas IMAT, PASS E AVER. O Fator4, as facetas AVER REAL, CONFLEX e IMUT. Em seguida, agruparamse os alunos da segunda e terceira séries do ensino médio para compará-los com os alunos da oitava série do ensino fundamental.

O procedimento adotado neste estudo corresponde a uma aplicação específica da ANOVA com medidas repetidas chamada na literatura de Análise de Perfis de Medidas Repetidas (Tabachinick \& Fidell, 1996). Essa análise procura responder se o perfil de médias em um conjunto de medidas (parte intra-sujeito do delineamento) é diferente para grupos distintos (parte entre-sujeitos do delineamento).

Pode-se conceber que os itens de um determinado fator propõem afirmações de um tema específico, e requerem do sujeito uma resposta indicando sua concordância com as afirmações. Portanto, o que está sendo medido, isto é, a variável dependente, é em essência, a concordância, em uma escala de sete pontos, com as afirmações propostas. Os escores de um participante nos quatro fatores representam seu perfil de concordância em relação aos quatro temas propostos. A análise de perfil busca investigar se o perfil de subgrupos de sujeitos definidos em função de alguma variável de interesse do pesquisador são distintos.

Em nosso caso tínhamos quatro grupos em função do tipo de escola, estadual e privada, e das séries, oitava e segundo-terceiro. Portanto a análise empregada foi a ANOVA $2 \times 2 \times 4$, tendo como variáveis independentes: o tipo de escola (estadual e privada), série (oitava e segundoterceiro) e os fatores do IDDP (Fator 1 ao Fator 4). Os níveis da última variável corresponderam aos diferentes conteúdos tratados pelos itens de cada fator e a variável dependente a concordância às afirmações propostas. Empregando esta análise estávamos interessados, prioritariamente, em verificar se existiam interações significativas de segunda ordem entre a variável Fatores e as variáveis Tipo de Escola e Séries. Tais efeitos, sendo significativos, indicam que o perfil de médias nos fatores do IDDP dependem do subgrupo sendo considerado.

Ainda, o efeito da variável Fatores, embora não seja alvo de interesse teórico, cumpre um papel importante do ponto de vista estatístico. Sabe-se que parte da variabilidade da concordância depende da conotação afetiva do item. Itens com conotações positivas evocam maior concordância e vice-versa (Clark \& Watson, 1995). Portanto, o efeito principal da variável Fatores, isto é, a diferença da concordância média aos itens dos fatores, está basicamente associado a este fato. Sua inclusão no modelo possibilita reduzir a variância de erro, pois, sendo significativo, explica uma parcela da variância removendoa do montante de erro, aumentando, portanto, o poder do teste estatístico. 
Tabela 6. Resultados da ANOVA Investigando o Efeito do Tipo de Escola (Escola), Série e Conteúdo dos Itens (Fatores) na Concordância com os Itens

\begin{tabular}{|c|c|c|c|c|c|c|}
\hline Fonte de variância & $S Q$ & $g l^{a}$ & $M Q$ & $F$ & $p$ & Eta $^{2}$ \\
\hline \multicolumn{7}{|l|}{ Entre grupos } \\
\hline Escola & 5,85 & 1 & 5,85 & 3,31 & 0,070 & 0,018 \\
\hline Série & 2,46 & 1 & 2,46 & 1,39 & 0,239 & 0,008 \\
\hline Escola X Série & 0,27 & 1 & 0,27 & 0,15 & 0,697 & 0,001 \\
\hline Erro & 319,67 & 181 & 1,77 & & & \\
\hline \multicolumn{7}{|l|}{ Intra sujeitos } \\
\hline Fatores & 120,21 & 2,81 & 42,70 & 62,23 & 0,000 & 0,256 \\
\hline Fatores X Escola & 7,27 & 2,81 & 2,58 & 3,77 & 0,012 & 0,020 \\
\hline Fatores X Série & 4,93 & 2,81 & 1,75 & 2,55 & 0,059 & 0,014 \\
\hline Fatores X Escola X Série & 3,55 & 2,81 & 1,26 & 1,84 & 0,143 & 0,010 \\
\hline Erro & 349,63 & 509,50 & 0,69 & & & \\
\hline
\end{tabular}

${ }^{a}$ Valores corrigidos pela fórmula de Greenhouse-Geisser para compensar a violação do postulado da simetria composta (Howell, 1997).

Os resultados da ANOVA são apresentados na Tabela 6. Pode-se observar que o conteúdo dos itens tem o maior efeito na concordância $(25,6 \%)$. Na Figura 1 estão apresentados graficamente os escores médios nos quatro fatores separadamente para os alunos das escolas públicas e particulares e da oitava e segunda-terceira séries. Notase claramente que a concordância é maior com os itens do Fator 2 e menor com os Fatores 1, 3 e 4. O teste $a$ posteriori de Newman-Keuls indicou que nas seis comparações possíveis entre as quatro médias nos fatores foram observadas diferenças significativas a nível 0,05 . Como foi colocado, os fatores que referem dificuldade evocam menor concordância quando comparados com o Fator 3 que não refere dificuldade. Um segundo efeito significativo observado foi o da interação Fatores X Tipo de Escola (2\%). Comparações entre os grupos das escolas pública e particular quanto ao nível de concordância com os itens de cada fator mostraram que os escores dos

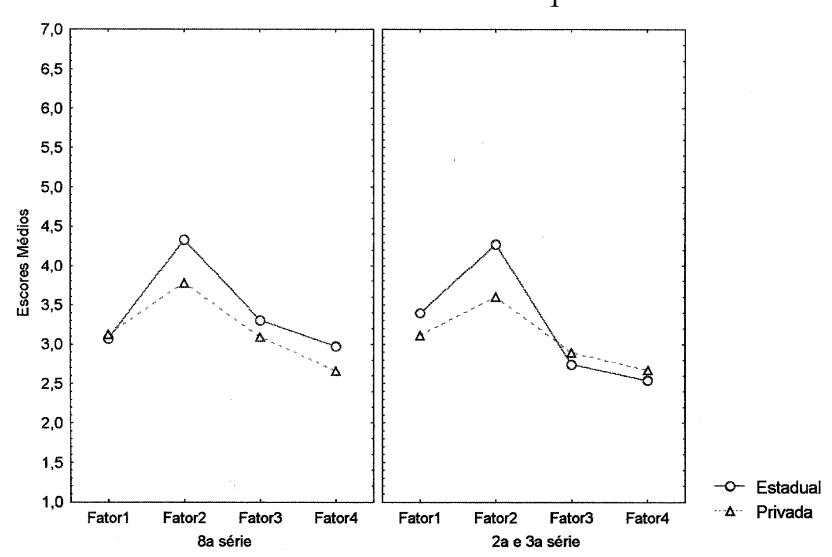

Figura 1. Escores médios nos quatro fatores gerais em função do tipo de escola e da série alunos da escola estadual no Fator 2 foram significativamente superiores aos dos alunos da escola particular, enquanto que para os demais fatores as diferenças observadas não foram significativas.

Estes resultados sugerem que os alunos de escola estadual tendem a valorizar mais o prestígio social e o aspecto econômico das profissões. Parecem depositar uma expectativa maior na profissão, provavelmente concebendo a escolha como um momento importante frente a uma possível mobilidade social desejada. Esse padrão nos indica uma configuração de valores que se assemelha, ao menos em alguns pontos, ao tipo Empreendedor do modelo de Holland (1963), embora não se possa considerar a busca de prestígio e retorno financeiro características exclusivas do tipo mencionado. Futuros estudos poderiam investigar se existem de fato diferenças nos interesses de estudantes de diferentes níveis sócio-econômicos e de que forma sua situação social pode estar determinando o espectro de suas aspirações profissionais. Além disso, pode-se questionar se a saliência de motivações econômicas na escolha profissional detectada entre os alunos da escola pública é positiva ou não, uma vez que opções profissionais consideradas segundo este critério podem não ser condizentes com as aptidões, desejos e demais valores dos sujeitos.

Como foi apontado anteriormente, seria esperado encontrar escores mais altos no Fator 3 entre alunos mais jovens. Essa hipótese foi testada especificamente por meio de um contraste linear comparando, somente no Fator 3 , os alunos da oitava série com os alunos da segundaterceira séries do Ensino Médio. A diferença encontrada foi significativa, $F(1,181)=3,87 ; p<0,05$, a favor da hipótese levantada. 
460 Ricardo Primi, Akicia Hernandez, Munboz, Cássia Aparecida Bighetti, Eliane Porto Di Nucci, Maria Carolina K. Pellegrini es Melissa Aparecida Moggi

\section{Conclusão}

Esse estudo apresenta o desenvolvimento de um inventário de levantamento das dificuldades da decisão profissional e explora, por meio de um estudo empírico, as propriedades psicométricas do inventário. A partir das principais definições do construto indecisão profissional selecionou-se o sistema taxonômico integrativo de Gat e colaboradores (1996) para a criação dos itens do inventário. Comparando a classificação inicial pelas categorias gerais (veja Tabela 1) com a classificação final obtida por meio da análise fatorial pode-se concluir que a última teve um alto nível de coerência com a categorização inicial. Na Tabela 7 apresenta-se a classificação inicial dos itens e as categorias definidas após a análise fatorial. Como pode ser observado, a maioria das categorias do sistema de Gati e colaboradores corresponderam aos conjuntos de itens distintos, agrupados nos fatores de primeira ordem do IDDP. Portanto, concluiu-se que o IDDP manteve-se coerente com a taxonomia de Gati e colaboradores. apresentaram consistências internas altas. Portanto, o IDDP consistiu em uma medida precisa de basicamente três aspectos da indecisão: a) a percepção de falta de informação e insegurança que possivelmente estão associadas a uma indefinição psicológica profissional Fator 1; b) a falta de preparo para a escolha - Fator 3; c) a existência de conflitos externos - Fator 4, e um aspecto relacionado ao tema motivacional da escolha enfocando o aspecto econômico e de prestígio social (Fator 2).

Uma primeira exploração do potencial diagnóstico do IDDP indica que ele captou diferenças sistemáticas entre alunos de idades e tipos de escola diferentes. Esses dados atestam o potencial do instrumento como provedor de informação aos profissionais que trabalham com orientação profissional, bem como para os pesquisadores na área. Sugere-se estudos mais sistemáticos dos perfis de escores nas 17 facetas e conseqüente verificação de sua utilidade informativa para a caracterização das dificuldades enfrentadas pelos jovens no momento da escolha.

Tabela 7. Comparação da Classificação Inicial com a Classificação Obtida pela Análise Fatorial

\begin{tabular}{|c|c|c|c|c|}
\hline \multirow[b]{2}{*}{$\begin{array}{l}\text { Classificação proposta pela } \\
\text { taxonomia de Gati, Krausz e } \\
\text { Osipow (1996) }\end{array}$} & \multicolumn{4}{|c|}{ Classificação estabelecida pela análise fatorial } \\
\hline & Fator 1 & Fator 2 & Fator 3 & Fator 4 \\
\hline \multicolumn{5}{|l|}{ Falta de preparo } \\
\hline Falta de Motivação & & & $\begin{array}{l}\text { AVER, PASS e } \\
\text { IMAT }\end{array}$ & AVER \\
\hline Indecisão & IND e INSEG & & & \\
\hline Mitos disfuncionais & & $\begin{array}{l}\text { ECON, SALV e } \\
\text { IMUT }\end{array}$ & & IMUT \\
\hline \multicolumn{5}{|l|}{ Falta de informação } \\
\hline Sobre o processo & INFO, ESTR & & PASS & \\
\hline Sobre o self & INFO, IND e INSEG & & & \\
\hline Sobre as profissões & INFO e ESTR & & & \\
\hline Sobre maneiras de obter inf. & ESTR & & & \\
\hline $\begin{array}{l}\text { Informações inconsistentes } \\
\text { Conflitos internos }\end{array}$ & $\begin{array}{l}\text { DIV, CONFLIN e } \\
\text { FINAM }\end{array}$ & NARCI & & REAL \\
\hline Conflitos externos & & & & \\
\hline
\end{tabular}

Conflitos externos

Nota. Ver Tabela 3 para entender as legendas.

Quanto às propriedades métricas, a análise fatorial dos itens indicou a existência de 17 fatores primários organizados hierarquicamente em quatro fatores mais gerais de segunda ordem. Esses fatores de segunda ordem
Uma limitação do IDDP refere-se aos fatores dificultosos de ordem social. O IDDP trata eminentemente dos fatores individuais que potencialmente podem levar à indecisão profissional. Entretanto, ele não 
trata dos fatores dificultosos da realidade social como, por exemplo, o conflito entre a aspiração por uma profissão e o mercado de trabalho restrito. Em versões futuras, sugere-se a sistematização desses fatores.

Em síntese, como instrumento de investigação dos fatores individuais da indecisão profissional, o IDDP mostrou-se promissor, incentivando o prosseguimento de seu uso em novos estudos.

\section{Referências}

Ackerman, P. L. (1996). A theory of adult intellectual development: Process, personality, interests, and knowledge. Intelligence, 22, 229-259.

Ackerman, P. L. \& Heggestad, E. D. (1997). Intelligence, personality, and interests: Evidence for overlapping traits. Psychological Bulletin, 121, 219-245.

Bordin, E. S. \& Kopplin, D. A. (1973). Motivational conflict and vocational development. Journal of Counseling Psychology, 20(2), 154-161.

Bohoslavsky, R. (1987). Orientaacão profissional: Teoria técnicas e ideologia. São Paulo: Cortez.

Carrol, J. B. (1985). Exploratory factor analysis: tutorial. Em D. K. Determan. (Org.), Current topics in buman intelligence: Research and methodology (Vol. 1, pp. 25-58). Worwoood, NJ: Ablex

Chartrand, J. M. \& Camp, C. (1991). Advances in the measurement of career development constructs: A 20-year review. Journal of Vocational Behaviour, 39, 1-39.

Clark, L. A. \& Watson, D. (1995). Constructing validity: Basic issues in objective scale development. Psychological Assessment, 7, 309-319.

Crites, J. O. (1969). Vocational psychology. New York: MacGraw-Hill.

Cronbach, L. J. (1996). Fundamentos da testagem psicologica. Porto Alegre: Artes Médicas.

Duarte, M. E. (1997). A avaliação em orientação e desenvolvimento da carreira. Em M. Gonçalves, I. Ribeiro, S. Araúio, C. Machado, L. S. Almeida \& M. Simões (Orgs), Avaliacĩo psicalógica: formes e coutextos (Vol. V pp. 385-391). Braga: Associnç̃o dos Psicólogos Portugueses (Vol. V, pp. 385-391). Braga. Associação dos Psicólogos Portugueses
(APPORT).

Gati, I. (1991). The structure of vocational interests. Psychological Bulletin, $109,309-324$
Gati, I., Krausz, M. \& Osipow, S. H. (1996). A taxonomy of difficulties in career decision making. Journal of Counseling Psychology, 43, 510-526. Holland, J. L. (1963). Explorations of a theory of vocational choice and achievement: II. A four-year prediction study. Psychological Reports, 12, $547-594$.

Holland, J. L. \& Powell, A. B. (1994). SDS career explorer: exploring your future with the SDS. Florida: Psychological Assessment Resources.

Howell, D. C. (1997). Statistical methods for psychology. Boston: Duxbury.

Mangas, S. L. (1997). Desarrollo de la madurez vocacional en la formación profesional específica. Em Associacão dos Psicólogos Portugueses e Colesio Oficial de Psicólogos de Españ (Or). A A Pos I Comes Colegio Oncial de Psicólogos de España (Org.), Actas, I Congresso Luso-Espanhol de Psicologia da Edurasăa (pp. 119-125). Coimbra: Associação os Psicólogos Portugueses (APPORT).

Müller, M. (1988). Orientagão vocacional. Porto Alegre: Artes Médicas.

Santos, C., Ribeiro, L. \& Campos, P. (1997). A promoção do desenvol vimento vocacional dos alunos - uma proposta da escola: a experiência de uma comunidade educativa. Em Associação dos Psicólogos Portugueses e Colegio Oficial de Psicólogos de España (Org.), Actas, I Congresso Luso-Espanbol de Psicologia da Educasão (pp. 101-105). Coimbra: APPORT.

Santos, P. J. (1997). Adolescência e indecisão vocacional. Dissertacão de Mestrado não-publicada. Curso de Psicologia, Universidade do Porto. Porto, Portugal.

Santos, P. J. \& Coimbra, J. (1994). Desenvolvimento psicológico e indecisão profissional. Cadernos de Consulta Psicológica, 10/11, 21-34.

Super, D. E. (1953). A theory of vocational development. American Psychologist, $8,185-190$

Tabachinick, B. G. \& Fidell, L. S. (1996). Using multivariate statistics. New York: HarperCollin

Vieira, S., \& Ferreira, J. A. (1997). Interesses e personalidade de alunos do ensino profissional. Em M. Gonçalves, I. Ribeiro, S. Araújo, C. Machado, L. S. Almeida \& M. Simões (Orgs.), Avaliagãa psicológica: Formas e contextos (Vol. V, pp. 351-358). Braga: Associação dos Psicólogos Portugueses (APPORT).

\section{Sobre os autores:}

Ricardo Primi é Psicólogo, Doutor em Psicologia Escolar e do Desenvolvimento Humano pela Universidade de São Paulo com parte desenvolvida na Yale University (EUA). Professor do Curso de Graduação e do Mestrado em Psicologia da Universidade São Francisco.

Alícia Maria Hernandez Munhoz é Psicóloga, Mestre em Psicologia Escolar pela PUCCAMP, Doutoranda em Psicologia Educacional pela UNICAMP e Professora do Curso de Graduação em Psicologia da Universidade São Francisco.

Cássia Aparecida Bighetti é Psicóloga, Mestre em Psicologia Escolar pela PUCCAMP e Professora do Curso de Graduação em Psicologia da Universidade São Francisco.

Eliane Porto Di Nucci é Psicóloga, Mestre em Psicologia Escolar pela PUCCAMP, Doutoranda em Psicologia Educacional pela UNICAMP e Professora do Curso de Graduação em Psicologia da Universidade São Francisco.

Maria Carolina Kussama Pellegrini é Psicóloga, Mestre em Educação pela USF e Professora do Curso de Graduação em Psicologia da Universidade São Francisco.

Melissa Aparecida Moggi é aluna do Curso de Graduação em Psicologia da Universidade São Francisco e Bolsista de Iniciação Científica pelo Programa de Bolsa-Auxílio à Pesquisa Científica (PROBAIC, USF). 
462 Ricardo Primi, Alicia Hernandez Munboz, Cássia Aparecida Bighetti, Eliane Porto Di Nucci, Maria Carolina K. Pellegrini es Melissa Aparecida Moggi

Anexo A

Itens do Inventário de Levantamento das Dificuldades da Escolha Profissional (IDDP)

Organizados segundo os Fatores Primários

\begin{tabular}{|c|c|c|}
\hline Fator & $\mathrm{N}^{\circ}$ do Item ${ }^{\text {a }}$ & Item \\
\hline \multirow[t]{8}{*}{ INFO } & 11 & Não sei que passos devo seguir para fazer uma boa escolha profissional. \\
\hline & 14 & Não tenho conhecimento das minhas habilidades. \\
\hline & 16 & Não sei quais profissões me atraem. \\
\hline & 17 & Não sei quais aspectos das profissões me atraem. \\
\hline & 18 & Não conheço bem as profissões existentes. \\
\hline & 44 & Não sei o que é mais importante considerar para a escolha de uma profissão. \\
\hline & $68^{*}$ & Tive experiências anteriores que me inspiraram a escolher uma determinada área profissional. \\
\hline & $80^{*}$ & O meu conhecimento sobre a minha opção profissional é suficiente para uma escolha certa. \\
\hline \multirow[t]{7}{*}{$\overline{\mathrm{IND}}$} & 07 & Tenho medo de fazer a escolha errada. \\
\hline & 15 & Não conheço minhas características de personalidade. \\
\hline & 36 & Em minha vida sinto dificuldade em tomar decisões sozinho. \\
\hline & 37 & Não decido sozinho, sempre preciso de ajuda. \\
\hline & 38 & Quando possível, evito compromissos pois não gosto de assumir responsabilidades. \\
\hline & 39 & Quando tenho que tomar uma decisão fico com medo de errar. \\
\hline & 63 & As opiniões de outras pessoas são essenciais na escolha da profissão. \\
\hline \multirow[t]{6}{*}{$\overline{\text { CONFLEX }}$} & 29 & Não sei se escolho a profissão que eu quero ou a que meus pais gostariam que eu escolhesse. \\
\hline & 30 & $\begin{array}{l}\text { Eu acho que tenho jeito para a profissão que escolhi, mas as pessoas que me conhecem bem não têm } \\
\text { a mesma opinião. }\end{array}$ \\
\hline & 31 & $\begin{array}{l}\text { Estou indeciso, pois a profissão que estou pensando é diferente da aconselhada pela minha familia } \\
\text { ou pessoas significativas para mim. }\end{array}$ \\
\hline & 32 & $\begin{array}{l}\text { Eu acho que possuo as características necessárias para a minha opção profissional, mas as outras } \\
\text { pessoas não concordam comigo. }\end{array}$ \\
\hline & 58 & Pessoas importantes para mim não aprovam minha escolha profissional. \\
\hline & $59 *$ & $\begin{array}{l}\text { Pessoas importantes para mim concordam com aquilo que acho importante na profissão que venho } \\
\text { pensando. }\end{array}$ \\
\hline \multirow[t]{4}{*}{$\overline{\mathrm{APO}}$} & 64* & Minha familia me ajuda sempre que tenho que tomar uma decisão importante. \\
\hline & $66^{*}$ & Preocupo-me com a opinião da minha família sobre a profissão que escolhi seguir. \\
\hline & $76^{*}$ & Minha familia tem tido um papel significativo na minha escolha profissional. \\
\hline & $78^{*}$ & A aprovação da família é essencial para a escolha de uma profissão. \\
\hline \multirow[t]{5}{*}{$\overline{\text { ESTR }}$} & 20 & Não sei como obter mais informações sobre minhas habilidades e características de personalidade. \\
\hline & 21 & Não sei o que fazer para conhecer melhor as profissões. \\
\hline & 43 & Não sei como combinar minhas características pessoais com as de uma profissão \\
\hline & $48^{*}$ & Conheço as características das profissões que me interessam. \\
\hline & 50 & Não sei onde conseguir mais informações sobre as profissões. \\
\hline \multirow[t]{5}{*}{$\overline{\mathrm{DIV}}$} & 23 & Estou bastante indeciso porque existem várias carreiras que são muito interessantes. \\
\hline & 25 & $\begin{array}{l}\text { É muito complicado escolher uma profissão porque, mesmo na profissão desejada, sempre existe } \\
\text { alguma coisa que eu não gosto. }\end{array}$ \\
\hline & 26 & Gosto de muitas coisas e não consigo encontrar uma profissão que satisfaça todos os meus interesses. \\
\hline & 52 & Meu problema é que há várias opções igualmente interessantes. \\
\hline & 55 & As coisas que realmente gosto de fazer não estão reunidas em uma só profissão. \\
\hline \multirow[t]{4}{*}{$\overline{\mathrm{REAL}}$} & $27^{*}$ & $\begin{array}{l}\text { Meu grande problema na escolha de uma profissão é: eu sei o que eu gosto, mas também sei que não } \\
\text { tenho as habilidades necessárias para a profissão desejada. }\end{array}$ \\
\hline & $53^{*}$ & Entre as profissões existentes, nenhuma realmente me atrai. \\
\hline & 62 & Nem todo o dinheiro do mundo substitui a realização profissional. \\
\hline & 74 & Não me importa o dinheiro desde que eu goste do que faço. \\
\hline
\end{tabular}




\begin{tabular}{|c|c|c|}
\hline \multirow[t]{4}{*}{ AVER } & 22 & O assunto "escolha profissional" me irrita. \\
\hline & 33 & Não sinto disposição para ficar pensando sobre a minha escolha profissional. \\
\hline & 34 & Acho que qualquer trabalho sempre é "chato". \\
\hline & 51 & Seria bom se não precisássemos escolher uma profissão. \\
\hline \multirow[t]{2}{*}{ CONFLIN } & 54 & $\begin{array}{l}\text { Há uma profissão que gosto, mas eu não teria jeito para realizar as atividades que as pessoas dessa } \\
\text { profissão fazem. }\end{array}$ \\
\hline & 56 & Existe uma profissão que me interessa, mas não tenho a habilidade necessária. \\
\hline \multirow[t]{5}{*}{$\overline{\mathrm{ECON}}$} & 09 & $\begin{array}{l}\text { Uma escolha profissional acertada faz com que a pessoa se realize completamente (financeira, pessoal } \\
\text { e socialmente). }\end{array}$ \\
\hline & 61 & A minha profissão deverá garantir o reconhecimento social, status e poder. \\
\hline & 70 & Devo escolher as profissões com melhores salários. \\
\hline & 71 & Preocupo-me muito em ser bem sucedido economicamente. \\
\hline & 81 & A escolha da profissão deve ser realizada levando-se em consideração a possibilidade de emprego. \\
\hline \multirow[t]{3}{*}{ PASS } & 03 & Se eu der tempo ao tempo, tenho certeza de que tomarei a decisão certa. \\
\hline & 12 & $\begin{array}{l}\text { Acho que não é necessário pensar muito sobre a escolha profissional, basta que eu verifique a que } \\
\text { mais me agrada. }\end{array}$ \\
\hline & 35 & Não preciso me preocupar, com o passar do tempo farei a escolha da profissão adequada. \\
\hline \multirow[t]{2}{*}{ SALV } & 08 & Uma profissão é a única maneira de resolver meus problemas. \\
\hline & 40 & Devo escolher uma profissão que me ajude a resolver meus problemas. \\
\hline \multirow[t]{3}{*}{ FINAM } & 24 & $\begin{array}{l}\text { O grande problema na minha escolha profissional é: o que eu quero fazer não é possível, e o que eu } \\
\text { posso fazer não me agrada. }\end{array}$ \\
\hline & 67 & Meus sonhos profissionais estão além da capacidade econômica de minha familia. \\
\hline & $79 *$ & Minha familia proporciona todo o suporte financeiro. \\
\hline \multirow[t]{3}{*}{ INSEG } & $04 *$ & Tomo decisões com facilidade. \\
\hline & $45^{*}$ & Tenho conhecimento de minhas habilidades para escolher uma profissão. \\
\hline & 46 & Não sei bem como eu sou. \\
\hline \multirow[t]{2}{*}{ IMAT } & 01 & Realmente não é a hora de fazer a escolha profissional. \\
\hline & 02 & $\begin{array}{l}\text { Nesse momento, existem coisas mais importantes com que me preocupar do que com o trabalho que } \\
\text { poderei exercer no futuro. }\end{array}$ \\
\hline \multirow[t]{3}{*}{$\overline{\mathrm{IMUT}}$} & 10 & $\begin{array}{l}\text { Se uma pessoa mudar de idéia depois que exerce uma profissão, dificilmente terá chances de se sair } \\
\text { bem na nova escolha. }\end{array}$ \\
\hline & 41 & Só existe um profissão que poderá satisfazer as minhas aspirações. \\
\hline & 42 & Sei que a minha escolha profissional deverá ser para o resto da minha vida. \\
\hline \multirow[t]{4}{*}{ NARCI } & 28 & O meu problema é que a profissão que escolhi é fácil. Não usarei as habilidades que tenho. \\
\hline & 65 & Meus amigos consideram minha opção profissional bastante interessante. \\
\hline & 73 & Devo escolher as profissões que possuem prestígio, isto é, valorizadas pela sociedade. \\
\hline & 77 & Meus colegas me admiram pela profissão que estou pensando seguir. \\
\hline
\end{tabular}

"Os asteriscos “*” indicam os itens cuja pontuação foi invertida na determinação dos escores. 


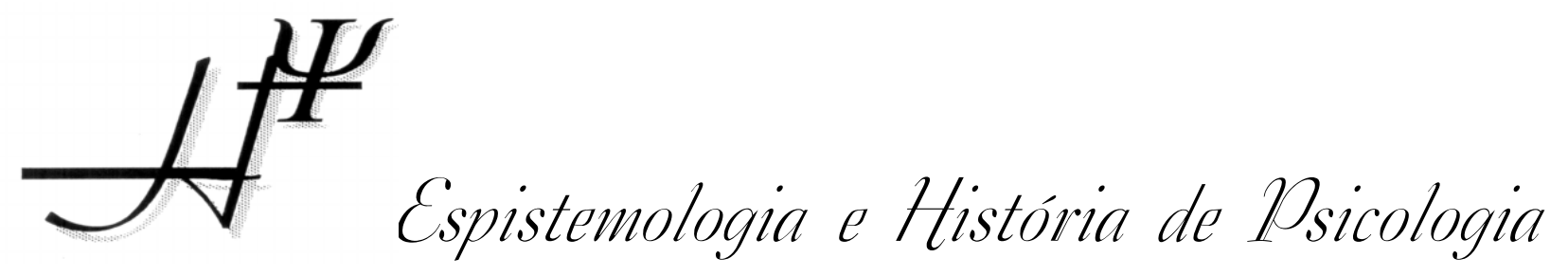

Um núcleo voltado ao estudo dos fundamentos conceituais da psicologia, à pesquisa historiográfica e ao ensino da história da psicologia em cursos de graduação.

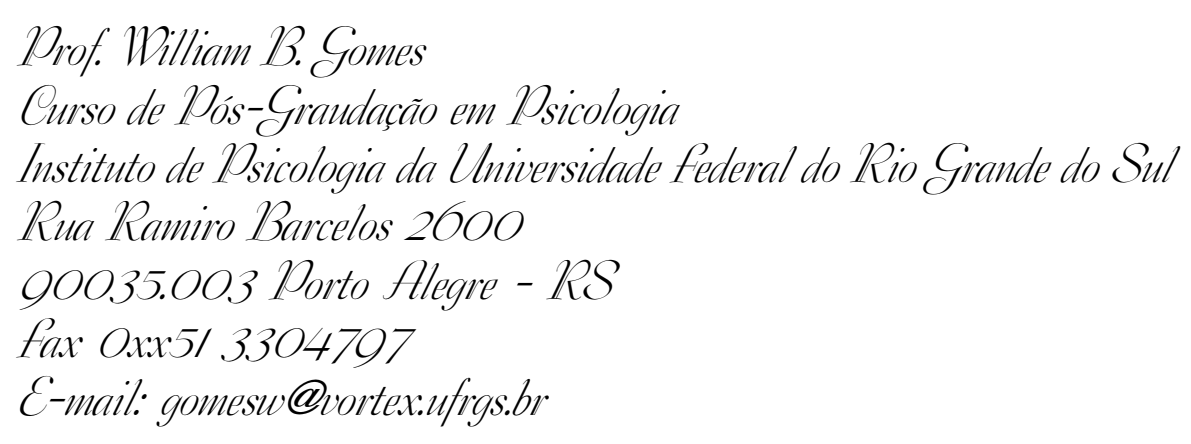

